\title{
Relationship between Helicobacter pylori and Rosacea: review and discussion
}

\author{
Xingzhe Yang (1)
}

\begin{abstract}
Background: Rosacea is an inflammatory disease affecting the central part of face characterized by persistent or recurrent episodes of erythema, papules, pustules and telangiectasias of unknown etiology. Helicobacter pylori (H. pylori) is a gram-negative bacillus, which is one of the main causes of chronic gastritis, gastric cancer and gastrointestinal ulcers. Recent evidences have suggested that $H$. pylori infection is closely related to the occurrence of diseases. In recent years, studies have found that Helicobacter pylori infection is associated with the occurrence of acne rosacea. So the treatment of Helicobacter pylori infection may be a therapeutic method of acne rosacea. But it continues to be controversial. In other studies, the treatment of Helicobacter pylori did not significantly reduce the severity of acne rosacea. To further explore the association between acne rosacea and Helicobacter pylori infection, a summarize method was used to study the relationship between acne rosacea and Helicobacter pylori, providing reference for clinical acne rosacea therapy.

Methods: Systematic searches were conducted on Wanfang Data, CQVIP, Springer, Public Health Management Corporation (PHMC), CNKI, and Pubmed, from January 1,2008 to Mar. 1, 2018, using Helicobacter pylori and rosacea to retrieve the literature. Depending on the inclusion and exclusion criteria, 27 articles considered or confirmed the correlation between H. pylori and rosacea.

Results: Epidemiological investigations and experiments have confirmed that $H$. pylori infection is associated with the development of rosacea. The effect of anti-H. pylori therapy is better than the routine therapy for rosacea. H. pylori can stimulate the immune system to produce a large number of inflammatory mediators, leading to the occurrence and aggravation of rosacea inflammation.

Conclusions: It is confirmed that $\mathrm{H}$. pylori infection is involved in the development of rosacea. It is suggested that rosacea patients should be tested for $\mathrm{H}$. pylori infection, the H. pylori-positive rosacea patients should be treated with eradication of H. pylori, so as to enhance the therapeutic effect of rosacea. This study adds that $\mathrm{H}$. pylori infection is involved in the development of rosacea. Epidemiological investigations and experiments have confirmed the rationality. The effect of anti-H. pylori therapy is better than the routine therapy for rosacea. H. pylori-positive rosacea patients should be treated with the therapeutic method of eradication of H. pylori.
\end{abstract}

Keywords: Rosacea, Helicobacter pylori, Related, Correlation, Epidemiological investigation, Experiment, Anti-H. pylori therapy, Mechanism 


\section{Background}

Rosacea is an inflammatory disease of unknown etiology, the role of $H$. pylori infection factor in the pathogenesis of rosacea has been paying close attention to epidemiological, experimental and clinical aspects of $H$. pylori, which has been confirmed that $H$. pylori infection is associated with the development of rosacea. But the data are limited, and further clinical and laboratory researches are required to assess the actual existence and relevance of many purported associations. That's already known about this topic which rosacea is an inflammatory disease affecting the central part of face of unknown etiology, affecting $12.3 \%$ Russians and 5.0\% Germans and 2.0\% 2.3\% Americans. As a gram-negative bacillus, $H$. pylori infection is closely related to the occurrence of diseases. This study adds that $H$. pylori infection is involved in the development of rosacea. Epidemiological investigations and experiments have confirmed the rationality. The effect of anti- $H$. pylori therapy is better than the routine therapy for rosacea. $H$. pylori-positive rosacea patients should be interpreted with eradication of $H$. pylori. Relationship between acne rosacea and Helicobacter pylori was studied, in order to provide reference for clinical acne rosacea therapy.

\section{Methods}

Systematic searches were conducted on Wanfang Data, CQVIP, Springer, Public Health Management Corporation
(PHMC), CNKI, and Pubmed, from January 1st 2008 up to now, using Helicobacter pylori and rosacea to retrieve the literature. The total number is 247:19 in Wanfang, 4 in CQVIP, 0 in Springer, 121 in PHMC, 2 in CNKI and 101 in Pubmed. Depending on the inclusion and exclusion criteria, 27 articles considered or confirmed the correlation between $H$. pylori and rosacea.

\section{Results}

More studies have shown that $H$. pylori is involved in the occurrence and development of Rosacea In recent years [1, 2]. Systematic researches were conducted on Wanfang Data, CQVIP, Springer, Public Health Management Corporation (PHMC), CNKI, and Pubmed, from January 1st 2008 up to now, using Helicobacter pylori and rosacea to retrieve the literature. The total number is 247:19 in Wanfang, 4 in CQVIP, 0 in Springer, 121 in PHMC, 2 in CNKI and 101 in Pubmed. Depending on the inclusion and exclusion criteria, 27 articles considered or confirmed the correlation between $H$. pylori and rosacea (Fig. 1).

\section{Discussion}

Rosacea is an inflammatory disease affecting the central part of face characterized by persistent or recurrent episodes of erythema, papules, papulo pustules and telangiectasias of unknown etiology [3]. It is divided into

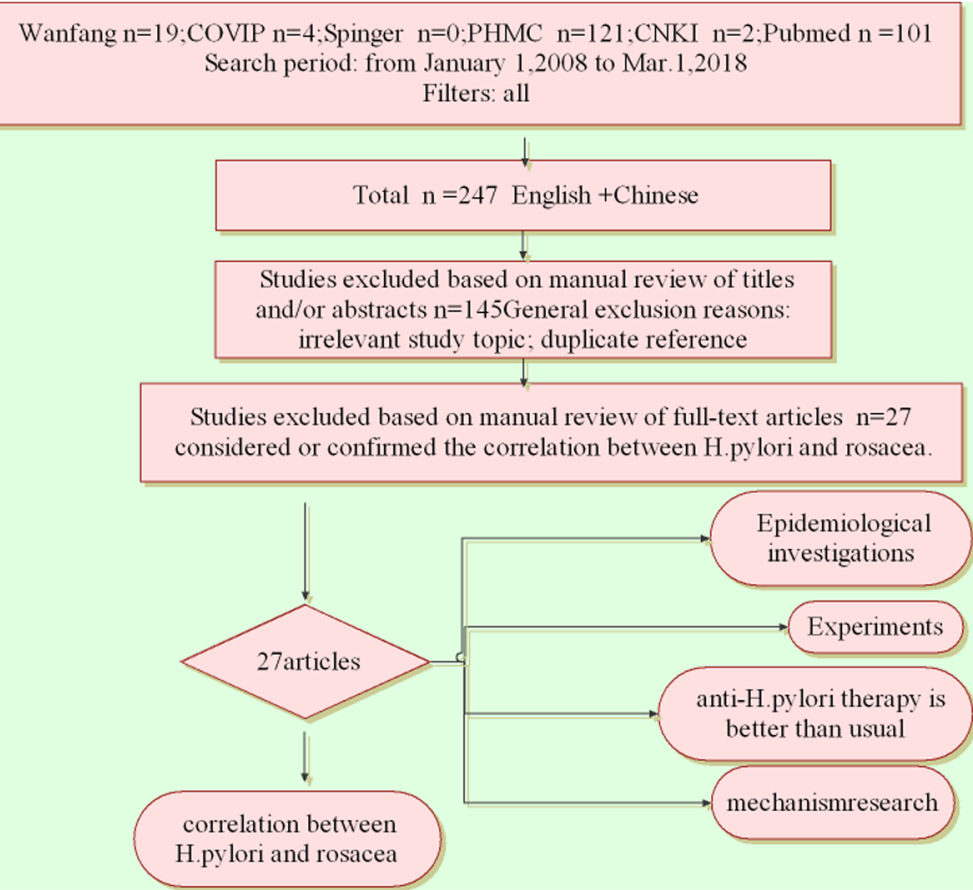

Fig. 1 Preferred reporting items for $\mathrm{H}$. pylori and rosacea. Systematic searches were conducted in Wanfang Data, CQVIP, Springer, Public Health Management Corporation (PHMC), CNKI and Pubmed, from January 1st 2008 to Mar. 1, 2018, using Helicobacter pylori and rosacea to retrieve the literature. The total is 247:19 in Wanfang, 4 in CQVIP, 0 in Springer, 121 in PHMC, 2 in CNKI and 101 in Pubmed. According to the inclusion and exclusion criteria, 27 articles considered or confirmed the correlation between $H$. pylori and rosacea. 
erythematotelangiectatic rosacea (ETR), papulopustular rosacea (PPR), phymatous rosacea (PHR) and ocular rosacea (OR) by American National Rosacea Society Expert Committee (NRSEC) [4] and Chinese Consensus on Diagnosis and Treatment of Rosacea 2016 [5]. Incidences of rosacea in Russia and Germany were 12.3 and 5.0\% [6], and 2.0\% 2.3\% [7] in the United States. The pathogenesis of rosacea is unclear and it may be caused by multifactorial chronic inflammation, which is dominated by innate immunity and abnormal vasomotor function [5].

Helicobacter pylori (H. pylori) is a gram-negative bacillus, which is one of the main causes of chronic gastritis, gastric cancer and gastrointestinal ulcers. Recent evidences have suggested that $H$. pylori infection played a role in the pathogenesis of a variety of skin diseases [8]. Egeberg A [9] performed a nationwide cohort study. A total of 49,475 rosacea patients and 4,312,213 general population controls were identified using nationwide administrative registers. Rosacea is associated with certain gastrointestinal diseases, but the possible pathogenic relevance is unknown.

\section{Epidemiological investigations have confirmed that $H$. pylori infection is associated with the development of rosacea}

Liu YF studied 50 rosacea patients [10] whose positive rate of $H$. pylori was significantly higher than that of healthy people. The efficacy of anti $H$. pylori treatment is much better than conventional treatment. It indicated that there is a certain relationship between Mongolian H. pylori and rosacea in the Inner Mongolia area.

Jørgensen AR found weak associations between rosacea and Helicobacter pylori infection as well as an effect of Helicobacter pylori therapy for rosacea symptoms, albeit that did not reach statistical significance. But analysis restricted to $\mathrm{C}$-urea-breath test showed a significant association (OR 3.12, 95\% CI 1.92-5.0, $p<0.0001$ ) [11]. Talebi Bezmin Abadi A assured the success of standard triple therapy to eradicate the bacterium because of a high rate of antibiotic resistance, and a better antibiotic therapy in the battle against $H$. pylori is needed. It needs further analysis before being able to change the current universal or even national guidelines in the treatment of any $H$. pylori-infected patients [12]. Yu JW studied the infestation rate of Helicobacter pylori and factors which had affected the infestation in the Inner Mongolian border recruits [13]. According to the consensus opinion of Maastricht-IV [14], Nine hundred Recruits aged 16 to 24 were enrolled in this cross-sectional study. $H$. pylori infection was detected by 13C-urea breath test, and the related risk factors were surveyed by using questionnaires. Logistic regression analysis revealed that halitosis with acne were positively correlated with $H$. pylori. The $H$. pylori infection rate of the recruits with acne was $47.2 \%$, which was higher than that of the recruits without acne whose rate was $46.8 \%$. But the difference was not statistically significant $\left(x^{2}=0.77, P=0.381\right)$. The $H$. pylori infection rate in recruits with oral odor and acne was $52.7 \%$, significantly higher than that in recruits without oral odor and acne whose rate was 39.7\% $\left(\mathrm{x}^{2}=18.96, P=0.008\right)$.

Wang AS [15] studied relationships between Helicobacter Pylori (Helicobacter Pylori)Infection and Acne Vulgaris in 980 cases of College Students, H. pylori was detected in 980 college students with acne and 260 college students without acne. The results showed that the H. pylori (H. pylori) positive rate of the acne group was $72.45 \%$. The positive rate of $\mathrm{H}$. pylori $(H$. pylori) was $39.23 \%$ in non-acne group. The difference was statistically significant $\left(x^{2}=\right.$ 100.3, $P<0.0001)$.

\section{Experiments show correlations between $H$. pylori infection and rosacea}

Yuan XR studied 42 rosacea patients and 33 acne vulgaris patients [16]. The level of serum specific IgG antibodies against $H$. pylori was determined, and the gastrointestinal symptoms of the patients were studied. 20 rosacea patients received the standard anti-H. pylori triple chemotherapy. The results showed that the serologic anti-H. pylori IgG level of the rosacea patients was higher than those of the controls, and gastrointestinal dysfunction was more frequent than those in the controls. The efficacy of anti- $H$. pylori therapy was also significantly better than usual. It indicates that $H$. pylori infection may be important in rosacea.

Szlachcic A [17] studied the relevance between $H$. pylori infection and rosacea. It concluded that $H$. pylori is closely connected with some digestive tract diseases and also the occurrence of some extra-gastrointestinal diseases. Studies confirmed the link between $H$. pylori infection and rosacea. The reason is perhaps that the toxic factor of $H$. pylori may cause delayed skin changes. It may be also possible that $H$. pylori directly induces complement activation and results in skin changes [18]. H. pylori can induce skin inflammation through two mechanisms. Firstly, H. pylori can affect skin physiological activities by increasing the concentration of nitrous oxide $\left(\mathrm{N}_{2} \mathrm{O}\right)$, Such as vasodilation, inflammation mediated and immune stimulation. Furthermore, $H$. pylori infection can also induce a specific cytotoxic reaction, through which can express cytotoxic genes A (cytotoxin-associated gene A, cagA), TNF- $\alpha$ and IL-8, and then induce a series of inflammatory reactions. H. pylori eradication can significantly alleviate the symptoms of rosacea, especially the subtype of pimples of papules. It wishes to point out a new direction for the treatment of rosacea patients. Bhattarai S's study of the prevalence of $H$. pylori in 26 rosacea patients indicates 
that $H$. pylori infection is positively correlated with rosacea [19].

Hong J observed detection rate of $H$. pylori Urase-IgG and H. pylori CagA-IgG in peripheral blood of 39 rosacea patients [20], the results showed that the total incidences of H. pylori Urase-IgG and H. pylori CagA-IgG in all 39 rosacea patients were not high, but the incidence rates in rosacea patients with digestive tract symptoms were $86.7 \%$ in $H$. pylori Urase-IgG and $80 \%$ in $H$. pylori CagA-IgG, which were significantly higher than that in rosacea patients without alimentary tract symptoms whose rates were 16.7 and $0 \%$. The results suggested that the virulent strain of $H$. pylori, especially the strain of $H$. pylori, may be involved in the occurrence and development of digestive tract symptoms and skin papules injury in rosacea. The results of El-khalawany $\mathrm{M}$ [1] showed that the positive rate of $H$. pylori in rosacea patients was significantly higher than that in normal controls, and the $H$. pylori infection rate in rosacea patients with dyspepsia was higher than that in patients with papular pustules,and that in patients with papular pustules was higher than that in patients with anectasis.

\section{The effect of anti-H. pylori therapy is better than the routine therapy for rosacea}

In patients with peripheral the lesions showed erythema, papules, pustule and possibly accompanied by gastrointestinal discomfort. The 13C-urea breath test for Helicobacter pylori screening was a good thing. After systemic anti- $H$. pylori (including PPI +2 antibiotics Bismuth) topical drug therapy and medical skin care products to repair the skin barrier,the results showed that perioral rosacea was associated with $\mathrm{H}$. pylori infection in the digestive tract. $H$. pylori was discovered in 84.1 , and $61.4 \%$ of patients who presented with digestive symptoms, which denote the relation between rosacea and digestive problems which confirm the study results of Sharma et al. [21] Rosacea is a skin disease with an obscure and complicated pathogenesis. Numerous mechanisms have been described, but its etiology remains an enigma. There is inadequate evidence regarding how determinant the role of $H$. pylori is. Built on the fact that the studies were not extensive, controlled studies are required [22]. The cure rates of $H$. pylori in rosacea patients and controls were $80 \%(16 / 20)$ and $85 \%(17 / 20)$, respectively [23].

Zhang HY [24] observed the therapeutic effect and mechanism of sequential therapy with the combination between Chinese and western medicine of $H$. pylori-positive acne rosacea (AR) with spleen-stomach dampness heat. Sixty qualified patients with spleen-stomach dampness, heat was equally randomized into a treatment group and control group. The clinical effective rate in the treatment group was significantly better than that in the control group $(P<0.05)$. The $H$. pylori-positive rate, concentrations of IL- 8 and TNF- $\alpha$ in serum was lower in the treatment group than in the previous treatment group, and the decrease was superior to control group $(P<0.01)$. AR has a certain relationship with $H$. pylori-positive rate. The sequential therapy with the combination between Chinese and western medicine could effectively relieve the clinical symptoms of $H$. pylori-positive AR patients with spleenstomach dampness-heat, and the mechanism of which is probably related to the decrease of $H$. pylori-positive rate and serum levels of IL- 8 and TNF- $\alpha$.

\section{Discussion}

Since 1999, when Szlachcics A [25] first proposed that rosacea infection was related to Helicobacter pylori infection, the role of $H$. pylori infection factors in the pathogenesis of rosacea has been paying close attention to the epidemiological, experimental and clinical aspects of Helicobacter pylori, which have been suggested or

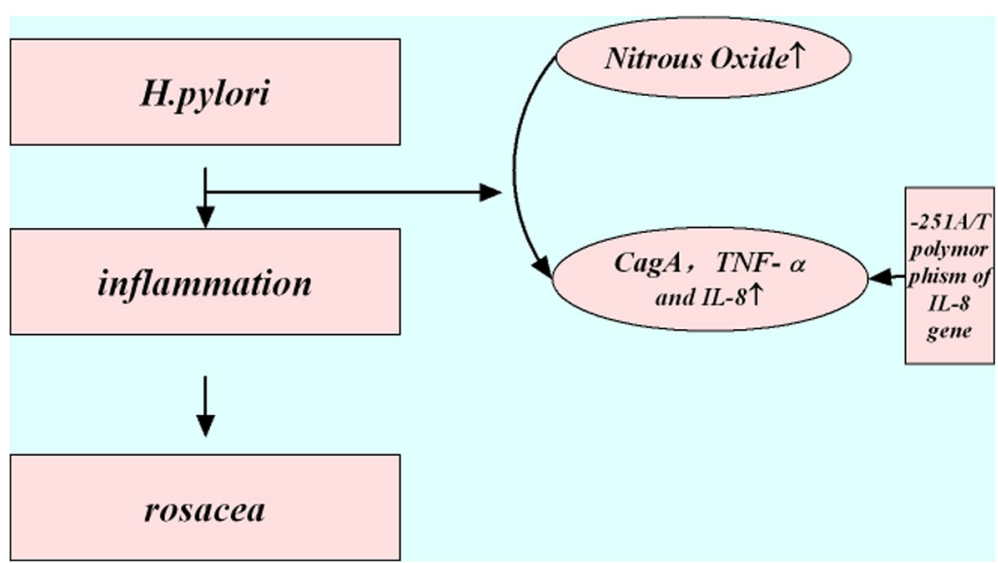

Fig. 2 Mechanism of $H$. pylori infection in relation to rosacea. The sequential therapy with the combination between Chinese and western medicine could effectively relieve the clinical symptoms of $H$. pylori-positive AR patients with spleen-stomach dampness-heat, and the mechanism of which is probably related to the decrease of $H$. pylori -positive rate and serum levels of IL- 8 and TNF- a 
confirmed that Helicobacter pylori infection is associated with the development of rosacea. The following studies illustrate the mechanism of Helicobacter pylori infection in relation to rosacea from the perspective of inflammation and genes.

It has been found that $H$. pylori infection is closely linked to the occurrence of diseases. H. pylori can stimulate the immune system to produce a large number of inflammatory mediators, leading to the occurrence and aggravation of rosacea inflammation [26]. As one of the infectious factors of rosacea [27], Extradermal bacteria, such as small intestinal bacteria, $H$. pylori can cause or exacerbate rosacea by producing large amounts of cytokines, especially papular pustules (PPR) [28].

At present, there are two mechanisms of skin inflammations induced by $H$. pylori. Firstly, $H$. pylori can affect skin physiological activities by increasing the concentration of Nitrous Oxide in vivo, such as vasodilation, inflammation and immune stimulation. Furthermore, $H$. pylori infection can also induce a specific cytotoxic reaction, which can express cytotoxic related genes A (cytotoxin-associated gene A, CagA), TNF- $\alpha$ and IL-8, and cause a series of inflammatory reactions [19].

From the perspective of gene research, Wang WW [29] studied the relationship between gene polymorphism and susceptibility to $H$. pylori. It concluded that $-251 \mathrm{~A} / \mathrm{T}$ polymorphism of IL-8 gene is closely related to the susceptibility of $\mathrm{T}$ Alleles which may be a risk factor for $H$. pylori infection.

Zhang Y [30] did the research on H. pylori gene in gastric mucosa of patients with rosacea. The expression of $H$. pylori gene in gastric mucosa of patients with different pathological types of rosacea is different, while rosacea is probably one of the symptoms caused by inflammatory mediators of IL-8 and IL-1 which induced by $H$. pylori virulence gene. But further clinical and laboratory researches are required to assess the actual existence and relevance of various purported associations.

There is a definite relationship between H. pylori and the occurrence and development of rosacea. It is speculated that $H$. pylori infection may play a role in the development of rosacea in diverse ethnic groups and may be an etiology of rosacea. Of course, as a multi-stage disease, the occurrence and development of the resource may not be determined only by one factor which may promote or play a decisive role in the development of the disease. Therefore, it is suggested that rosacea patients should be tested for $H$. pylori infection, the $H$. pylori-positive rosacea patients should be treated with eradication of $H$. pylori, so as to enhance the therapeutic effect of rosacea (Fig. 2).

\section{Conclusions}

$H$. pylori infection is associated with the development of rosacea. The effect of anti- $H$. pylori therapy is better than the routine therapy for rosacea. $H$. pylori-positive rosacea patients should be treated with eradication of $H$. pylori.

\section{Abbreviations}

Anti-H. pylori: Anti Helicobacter pylori; H. pylori.(H. pylori): Helicobacter pylori(Helicobacter pylori);

H. pylori-positive: Helicobacter pylori positive

\section{Acknowledgements}

I gratefully acknowledge the predecessors whose achievements have provided valuable references and inspiration for this study.

\section{Availability of data and materials}

All original data and materials are available upon request from the corresponding author.

\section{Authors' contributions}

YXZ carried out the research design, data collection and analysis, drafting and revision of the final manuscript. The author read and approved the final manuscript.

\section{Ethics approval}

Given the study was a comprehensive research rather than animal experimental research, no need for the approval of the ethics committee. The findings and conclusions in this report are those of the author and do not necessarily represent the official position of BMC Infectious Diseases.

Consent for publication

Not applicable.

\section{Competing interests}

The author declares that he/she has no competing interests.

\section{Publisher's Note}

Springer Nature remains neutral with regard to jurisdictional claims in published maps and institutional affiliations.

Received: 4 March 2018 Accepted: 3 July 2018

Published online: 11 July 2018

\section{References}

1. El-Khalawany M, Mahmoud A, Mosbeh AS, et al. Role of helicobacter pylori, in common rosacea subtypes: a geno-typic comparative study of Egyptian patients. Dermatol. 2012;39(12):989-95.

2. Gravina AG, Federico A, Ruocco E, et al. Helicobacter pylori infection but not small intestinal bacterial overgrowth may play a pathogenic role in rosacea. United European Gastroenterol J. 2015;3(1):17-24.

3. Schwab VD, Sulk M, Seeliger $S$, et al. Neurovascular and neuroim-mune aspects in the pathophysiology of rosacea. J Invest Dermatol. 2011;15:53-62.

4. Crawford GH, Pelle MT, James WD. Rosacea: I. Etiology, pathogenesis, and subtype classification. J Am Acad Dermatol. 2004;51(3):327-41; quiz 342-4. PMID: 15337973. https://doi.org/10.1016/j.jaad.2004.03.030.

5. Subprofessional Committee of Dermatologists Branch of Chinese Physicians Association. Consensus on diagnosis and treatment of Rosacea in China 2016. Chinese J Dermatol. 2017;50(3):156-61. Available at:https://wenku. baidu.com/view/6d0dc5c8dc88d0d233d4b14e852458fb760b3812.html

6. Tan J, Schäfer H, Araviiskaia E, et al. Prevalence of rosacea in the general population of Germany and Russia-the RISE study. J Eur Acad Dermatol. 2016;30(3):428-34

7. Gupta MA, Gupta AK, Chen SJ, et al. Comorbidity of rosacea and depression: an analysis of the National Ambulatory Medical Care Survey and National Hospital Ambulatory Care Survey-Outpatient Department data collected by the U.S.National Center for Health Statistics from 1995 to 2002. Brit J Dermatol. 2005;153(6):1176-81.

8. Hernando-Harder Ana C, Booken N, Goerdt S, et al. Helicobacter pylori infection and dermatologic diseases. Eur J Dermatol. 2009;19(5):431-44. PMID:19527988. https://doi.org/10.1684/ejd.2009.0739.

9. Egeberg A, Weinstock LB, Thyssen EP, et al. Rosacea and gastrointestinal disorders: a population-based cohort study. Meier Br J Dermatol. 2017;176:9-10. 
10. Liu YF, Hao Y, Shi JH, et al. A study of Helicobacter pylori infection in Mongolian nationality patients with rosacea in Inner Mongolia. Guangdong Med J. 2012;33(3):355-6. Available at:http://kns.cnki.net/KCMS/detail/detail. aspx? dbcode $=$ CJFQ\&dbname $=$ CJFD2012\&filename $=$ GAYX201203027\&V= MTc4NzZVTC9OSWI6U2RyRzRIOVBNckk5SFkOUjhIWDFMdXhZUzdEaDFU M3FUcldNMUZyQ1VSTEtmWXVackZDam0=\&UID=WEEvREcwSIJ HSIdTTEYZVnB3ZDE1Vy9PaURQNGICT0gxai9xSnpiRmpEVT0\%3d\%249A4hF_ YAuvQ5obgVAqNKPCYCEjKensW4IQMovwHtwkF4WYPoHbKxJw!!\&autoLogin=0.

11. Jørgensen $A R$, Egeberg $A$, Gideonsson $R$, et al. Rosacea is associated with helicobacter pylori: a systematic review and meta-analysis. J Eur Acad Dermatol Venereol. 2017;31(12):2010-5. PMID: 28543746. https://doi.org/ 10.1111/jdv.14352.

12. Talebi Bezmin Abadi A.Comment on "effects of helicobacter pylori treatment on rosacea: a single-arm clinical trial study".J Dermatol 2017; $\cdots:$. 1. https://doi. org/10.1111/1346-8138.13999.

13. Yu JW, An HJ, Su H, Xie H, Yang L, et al. Analysis of infestation rate of Helicobacter pylori and factors affecting the infestation in Inner Mongolia border recruits. Med J Chin PLA. 2014;39(9):760-3. Available at:http://kns. cnki.net/KCMS/detail/detail.aspx?dbcode $=$ CJFQ\&dbname=CJFD2014\& filename=JFJY201409018\&uid=WEEvREcwSIJHSIdTTEYZVnB3ZDE1 Vy9PaURQNGICTOgxai9xSnpiRmpEVT0=\$9A4hF_YAuvQ5obgVAqNKPCY cEjKensW4IQMovwHtwkF4VYPoHbKxJw!!\&v=MjI2OTQ5RWJJUjhIWDFM dXhZUzdEaDFUM3FUcldNMUZyQ1VSTEtmWXVackZDam1XNy9PTHI2 QmQ3RzRIOVhNcG8=.

14. Liu WZ, Xiao SD. Interpretation of new international consensuses on helicobacter pylori. Chin J Gastroenterol. 2012;17(1):1-4. Available at: http://kns.cnki.net/KCMS/detail/detail.aspx?dbcode=CJFQ\&dbname= CJFD2012\&filename=WIEC201201002\&uid=WEEvREcwSIJHSIdTTEY zVnB3ZDE1Vy9PaURQNGICTOgxai9xSnpiRmpEVT0=\$9A4hF_ YAuvQ5obgVAqNKPCYcEjKensW4IQMovwHtwkF4VYPoHbKXJw!!\&V= MTEOMZdXTTFGckNVUkXLZII1WnJGQ2puVnlvTU1pVE9iY kcOSDIQTXJVOUZab1|4ZVgxTHV4WVM3RGgxVDNxVHI=

15. Wang AS. Relationship between Acne vulgaris and Helicobacter pylori infection in College students. Chin J Derm Venereol. 2016;30(10):1024-5. https://doi.org/10.13735/j.cjdv.1001-7089.201602063. Available at: http://kns.cnki.net/KCMS/detail/detail.aspx?dbcode=CJFQ\&dbname= CJFDLAST2017\&filename=ZBFX201610011\&uid=WEEvREcwSIJHSId TTEYZVnB3ZDE1Vy9PaURQNGICTOgxai9xSnpiRmpEVT0=\$9A4hF YAuvQ5obgVAqNKPCYcEjKensW4IQMovwHtwkF4VYPoHbKxJw!!\&v= MTk2MTgVQVB5L05kckc0SDImTnI0OUVaWVI4ZVgXTHV4W VM3RGgxVDNxVHJXTTFGckNVUkxLZII1WnJGQ2poVXI=.

16. Yuan XR, Gu FX. Correlation of helicobacter pylori infection with rosacea. J Clin Dermatol. 2000;29(1):18-20. Available at: http://kns.cnki.net/KCMS/ detail/detail.aspx?dbcode=CJFQ\&dbname=CJFD2000\&filename $=$ LCPF200001010\&uid=WEEvREcwSIJHSIdTTEYZVnB3ZDE1Vy9Pa URQNGICTOgxai9xSnpiRmpEVT0=\$9A4hF_YAuvQ5obgVAqNKPCYC EjKensW4IQMovwHtwkF4VYPoHbKxJw!!\&v=MDUyOThSOGVYMUx1eFITNORo MVQzcVRyV00xRnJDWJMS2ZZdVpyRkNqaFZydkpLUzdiYUxHNEh0 SE1ybzlFWkk=

17. Szlachcic A. The link between helicobacter pylori infection and rosacea. J Eur Acad Dermatol Venereol. 2002;16(4):328-33.

18. Dundon WG, de Bernard M, Montecucco C. Virulence factors of helicobacter pylori. Int J Med Microbiol. 2001;290(8):647-58.

19. Bhattarai S, Agrawal S, Rijal A, et al. The study of prevalence of helicobacter pylori in patients with acne rosacea. Kathmandu Univ Med J. 2014;10(4):49-52.

20. Hong J. Incidence and Clinical significance of Helicobacter pylori Associated protein Antibody in Peripheral Blood of 39 patients with rosacea. Gui Zhou Med. 2014;38(6):541-2. Available at: http://kns.cnki.net/KCMS/detail/detail. aspx?dbcode=CJFQ\&dbname=CJFD2014\&filename $=$ GZYI201406024\&uid $=$ WEEVRECWSIJHSIdTTEYZVnB3ZDE1Vy9PaURQNGICTOgxai9xSnpiRmpEVT0= \$9A4hF_YAuvQ5obgVAqNKPCYCEjKensW4IQMovwHtwkF4VYPoHbKxJw!!\&v= MTUOMTZWN3pNSWpmU103RzRIOVhNcVk5SFIJUjhIWDFMdXh

ZUzdEaDFUM3FUcldNMUZyQ1VSTEtmWXVackZDdmw=.

21. Sharma VK, Lynn A, Kaminski M, et al. A study of the prevalence of helicobacter pylori infection and other markers of upper gastrointestinal tract disease in patients with rosacea. Am J Gastroenterol. 1998;93(2):220-2. PMID: 9468246. https://doi.org/10.1111/j.1572-0241.1998.00220.x.
22. Lazaridou E, Korfitis C, Rosacea KC. Helicobacter pylori: links and risks. Clin Cosmet Investig Dermatol. 2017;10:305-10. PMID: 28848358 PMCID: PMC5556181. https://doi.org/10.2147/CCID.S121117.

23. Herr $\mathrm{H}$, You $\mathrm{CH}$. Relationship between helicobacter pylori and rosacea: it may be a myth. J Korean Med Sci. 2000;15(5):551-4. PMID: 11068993. PMCID: PMC3054671. https://doi.org/10.3346/jkms.2000.15.5.551.

24. Zhang HY, Chen L, Cao Y, et al. Clinical Observation of Integrated Chinese and Western edicineSequential Therapy for Treatment of Hp-positive Acne Rosacea. J New Chinese Med. 2013;45(4):81-3. Available at: http://www. cqvip.com/QK/94050X/201304/45120370.html.

25. Szlachcic A, Sliwowski Z, Karczewska E, et al. Helicobacter pylori and its eradication in rosacea. J Physiol Pharmacol. 1999;50(5):777-86. PMID: 10695558. Available at: https://www.ncbi.nlm.nih.gov/pubmed/10695558

26. Argenziano G, Donnarumma G, lovene MR. Incidence of anti- helicobacter pylori and anti- CagA antibodies in rosacea patients. Int J Dermatol. 2003;42(8):601-4.

27. Hao F, Song ZQ. Clinical research progress of Rosacea in 2016. J Dermatol Venereol. 2017;39(1):18-9. Available at: http://kns.cnki.net/KCMS/detail/detail. aspx? $\mathrm{dbcode}=\mathrm{CJFQ} \& \mathrm{dbname}=$ CJFDLAST2017\&filename $=$ PFBX201701010\&v $=$ MzE0OTIBTIN2SmRyRzRIOWJNcm85RVpJUjhIWDFMdXhZUzdEaDFUM3 FUcldNMUZyQ1VSTEtmWXVacUZpbmdVYnl=.

28. Drago F, De Col E, Agnoletti AF, et al. The role of small intesti-nal bacterial overgrowth in rosacea: a 3-year follow -up. J Am Acad Dermatol. 2016:75(3):e113-5.

29. Wang $\mathrm{WW}$, Wu CY, Zhao SY. Correlation between -251A/T polymorphism of IL-8 and susceptibility of helicobacter pylori. Hainan Medicine. 2013:24(16):2344-5. Available at: http://kns.cnki.net/KCMS/detail/detail.aspx?dbcode=CJFQ\& dbname $=$ CJFD2013\&filename=HAIN201316004\&v=MzEONjIEaDFUM 3FUcldNMUZyQ1VSTEtmWXVacUZpbmdXN3ZMTFN6Q1IMRzRIOU xOCVk5RIIJUjhIWDFMdXhZUZC=.

30. Zhang Y, Liu H, She FF, et al. Detection and mechanism of helicobacter pylori gene in gastric mucosa of patients with rosacea. J Fujian Med. 2016;38(1):53-6. Available at: http://kns.cnki.net/KCMS/detail/detail. aspx?dbcode $=$ CJFQ\&dbname $=$ CJFDLAST2016\&filename $=$ FJYY201601024\& $=$ MjA5NzdXTTFGckNVUkxLZII1WnFGaW5oVnlzTkI5ZINkN0c0SDImTXJ VOUhZSVI4ZVgxTHV4WVM3RGgxVDNxVHI=.

\section{Ready to submit your research? Choose BMC and benefit from:}

- fast, convenient online submission

- thorough peer review by experienced researchers in your field

- rapid publication on acceptance

- support for research data, including large and complex data types

- gold Open Access which fosters wider collaboration and increased citations

- maximum visibility for your research: over $100 \mathrm{M}$ website views per year

At BMC, research is always in progress.

Learn more biomedcentral.com/submissions 